\title{
The clinical relevance of omega-3 fatty acids in the management of hypertriglyceridemia
}

\author{
James Backes ${ }^{1 *}$, Deborah Anzalone ${ }^{2}$, Daniel Hilleman ${ }^{3}$ and Julia Catini ${ }^{2}$
}

\begin{abstract}
Hypertriglyceridemia (triglycerides $>150 \mathrm{mg} / \mathrm{dL}$ ) affects $~ 25 \%$ of the United States (US) population and is associated with increased cardiovascular risk. Severe hypertriglyceridemia ( $\geq 500 \mathrm{mg} / \mathrm{dL}$ ) is also a risk factor for pancreatitis. Three omega-3 fatty acid (OM3FA) prescription formulations are approved in the US for the treatment of adults with severe hypertriglyceridemia: (1) OM3FA ethyl esters (OM3EE), a mixture of OM3FA ethyl esters, primarily eicosapentaenoic acid (EPA) and docosahexaenoic acid (DHA) (Lovaza ${ }^{\oplus}$, Omtryg $^{\mathrm{TM}}$, and generics); (2) icosapent ethyl (IPE), EPA ethyl esters (Vascepa ${ }^{\circledast}$ ); and (3) omega-3 carboxylic acids (OM3CA), a mixture of OM3FAs in free fatty acid form, primarily EPA, DHA, and docosapentaenoic acid (Epanova ${ }^{\oplus}$ ). At approved doses, all formulations substantially reduce triglyceride and very-low-density lipoprotein levels. DHA-containing formulations may also increase low-density lipoprotein cholesterol. However, this is not accompanied by increased non-high-density lipoprotein cholesterol, which is thought to provide a better indication of cardiovascular risk in this patient population. Proposed mechanisms of action of OM3FAs include inhibition of diacylglycerol acyltransferase, increased plasma lipoprotein lipase activity, decreased hepatic lipogenesis, and increased hepatic $\beta$-oxidation. OM3CA bioavailability (area under the plasma concentration-time curve from zero to the last measurable concentration) is up to 4-fold greater than that of OM3FA ethyl esters, and unlike ethyl esters, the absorption of OM3CA is not dependent on pancreatic lipase hydrolysis. All three formulations are well tolerated (the most common adverse events are gastrointestinal) and demonstrate a lack of drug-drug interactions with other lipid-lowering drugs, such as statins and fibrates. OM3FAs appear to be an effective treatment option for patients with severe hypertriglyceridemia.
\end{abstract}

Keywords: Docosahexaenoic acid, Docosapentaenoic acid, Eicosapentaenoic acid, Hypertriglyceridemia, Omega-3 fatty acids

\section{Background}

Hypertriglyceridemia, defined as a triglyceride (TG) level of $>150 \mathrm{mg} / \mathrm{dL}$, affects approximately $25 \%$ of the United States (US) population [1]. High levels of TG $(\geq 200 \mathrm{mg} / \mathrm{dL}$ ) have been shown to be independently associated with an increased risk of cardiovascular disease (CVD), even in patients treated effectively with statins to reduce low-density lipoprotein cholesterol (LDL-C) $[2,3]$.

\footnotetext{
* Correspondence: jbackes@kumc.edu

NB: Although Epanova and Omtryg have been approved in the US by the Food and Drug Administration, and Epanova is currently being studied in the prevention of cardiovascular outcomes, they are not yet commercially available.

'Atherosclerosis and LDL-Apheresis Center, School of Pharmacy, University of Kansas, 3901 Rainbow Boulevard, Kansas City, KS 66160, USA

Full list of author information is available at the end of the article
}

With increased TG, there are elevations of TG-rich lipoproteins (TRL) (very-low-density lipoproteins [VLDL] plus chylomicrons) and their remnants which have been shown to contribute to the progression of atherosclerosis and CVD via a number of direct and indirect mechanisms. These mechanisms include the direct contribution to intimal cholesterol deposition, and the activation and enhancement of pro-inflammatory, pro-apoptotic, and pro-coagulant pathways [4].

Severe hypertriglyceridemia, defined by the 2014 National Lipid Association (NLA) guidelines as a TG level of $\geq 500 \mathrm{mg} / \mathrm{dL}$ [5], is also a well-known risk factor for pancreatitis, reportedly causing up to $7 \%$ of cases [6]. Severe hypertriglyceridemia usually occurs as a result of one or more genetic disorders, such as 
hyperlipoproteinemia or lipoprotein lipase (LPL) deficiency [7]. In this instance, elevated levels of chylomicrons are thought to obstruct capillaries in the pancreas, leading to local ischemia, edema, and inflammation [6].

Consequently, it is important that patients with hypertriglyceridemia receive safe and effective treatment to reduce the risk of pancreatitis and CVD. In severe hypertriglyceridemia, guidelines advocate the immediate use of TGlowering drugs $[5,8]$, which include fibrates, niacin, and omega-3 fatty acids (OM3FAs). However, in patients with moderately elevated TG, statins are often recommended as first-line therapy. Although statins primarily target elevated LDL-C, in patients with high baseline TG levels ( $\geq 273 \mathrm{mg} /$ $\mathrm{dL}$ ), some high-intensity statins have been shown to reduce TG by up to $43 \%$ [9]. That said, if elevated TG or nonhigh-density lipoprotein cholesterol (non-HDL-C) levels persist following lifestyle intervention and statin therapy, a number of guidelines recommend the addition of a TGlowering drug [5]. Although all of these drugs successfully lower TG levels, the high incidence of adverse events associated with niacin therapy and the increased incidence of myopathy and rhabdomyolysis observed with some fibratestatin combinations have raised concerns [10, 11]. In April 2016, the Food and Drug Administration (FDA) concluded that the benefits of the concomitant use of statins plus extended release niacin or some fibrates do not outweigh the risks, and have, therefore, withdrawn the approvals for this indication [12]. However, the indications for the treatment of severe hypertriglyceridemia remain intact. It has been suggested that OM3FAs may be a well-tolerated and effective alternative to fibrates and niacin in the treatment and management of hypertriglyceridemia [13].

Prescription formulations of OM3FAs are indicated in the US as an adjunct to diet to reduce TG levels in adults with severe hypertriglyceridemia. There are three prescription OM3FA formulations approved in the US: (1) omega3 fatty acid ethyl esters (OM3EE), a mixture of long-chain omega-3 fatty acid ethyl esters, primarily eicosapentaenoic acid (EPA) and docosahexaenoic acid (DHA) (Lovaza ${ }^{\circ}$, Omtryg $^{\text {Tw }}$, and some generics) $[14,15]$; (2) icosapent ethyl (IPE), EPA ethyl esters (Vascepa ${ }^{\circ}$ [16]; (3) and omega-3 carboxylic acids (OM3CA), a mixture of long-chain OM3FAs in free fatty acid form, primarily EPA, DHA, and docosapentaenoic acid (DPA) (Epanova ${ }^{\circ}$ ) [17]. Of note, although Epanova and Omtryg have been approved in the US by the FDA, and Epanova is currently being studied in the prevention of adverse cardiovascular outcomes, they are not yet commercially available. Although these prescription formulations have all been shown to significantly reduce TG levels in patients with high or very high TG levels, and they appear to be generally well tolerated in these patient populations, they differ in their effects on individual lipid parameters and bioavailability [18-24]. OM3FA dietary supplements are also available, but as these products do not need to comply with the rigorous regulations required for prescription formulations, and do not require approval from the FDA, their OM3FA content is often inconsistent and may be inadequate to effectively treat hypertriglyceridemia [25-27].

This review aims to evaluate the clinical relevance of OM3FAs in the management of hypertriglyceridemia and to explore the pharmacological and mechanistic properties, as well as the efficacy and safety, of three prescription OM3FA formulations.

\section{Search strategy}

A search of PubMed was performed using the following search strategy: ("Hypertriglyceridemia" $[\mathrm{MeSH}]$ ) AND "Fatty Acids, Omega-3" [MeSH]).

The search was limited to English-language, humanonly studies published from August 17, 2005, to August 17,2015 . The literature search yielded a total of 166 publications. The reference lists of articles identified using this search strategy were also searched, meaning that widely referenced, older publications were also screened. Articles were deemed eligible for inclusion if they provided useful and clinically relevant information pertaining to prescription formulations of OM3FAs, or the treatment and management of hypertriglyceridemia. In addition, the US prescribing information for prescription OM3FAs and current guidelines on the treatment and management of dyslipidemia were reviewed.

\section{Management of hypertriglyceridemia}

The clinical definitions of hypertriglyceridemia, as outlined in the 2014 NLA guideline on the management of dyslipidemia, are shown in Table 1 . However, it is important to note that the precise clinical definitions of the severity of hypertriglyceridemia differ among guidelines. For example, although severe hypertriglyceridemia is typically classified as a TG level $\geq 500 \mathrm{mg} / \mathrm{dL}[5,28-30]$, the 2012 Endocrine Society guideline and the 2014 American Diabetes Association guideline classify severe hypertriglyceridemia as a TG level $\geq 1000 \mathrm{mg} / \mathrm{dL}$ [31, 32]. The majority of guidelines agree that a TG level of $<150 \mathrm{mg} / \mathrm{dL}$ is desirable [5, 28-31, 33, 34].

Although current guidelines advocate the immediate use of a TG-lowering drug in patients with very high TG levels $(\geq 500 \mathrm{mg} / \mathrm{dL})$ and recommend that lifestyle intervention

\section{Table 1 Clinical definition of hypertriglyceridemia [5]}

\begin{tabular}{ll}
\hline Category & $\mathrm{TG}, \mathrm{mg} / \mathrm{dL}(\mathrm{mmol} / \mathrm{L})$ \\
\hline Normal & $<150(<1.7)$ \\
Borderline-high & $150-199(1.7-2.2)$ \\
High & $200-499(2.2-5.6)$ \\
Very high (severe HTG) & $\geq 500(\geq 5.6)$ \\
\hline
\end{tabular}

HTG hypertriglyceridemia, TG triglyceride 
and statin treatment should be considered as first-line therapy in patients with moderately elevated TG, they can vary in some aspects of their treatment and management recommendations [5, 28-31, 33, 34]. The 2014 NLA guideline recommends using LDL-C or non-HDL-C as the primary treatment target in patients with dyslipidemia. They also emphasize that as non-HDL-C comprises all the cholesterol carried by potentially atherogenic lipoprotein particles, it is a stronger predictor of CVD than LDLC. In addition, they consider apolipoprotein B (ApoB) as an optional secondary treatment target [5]. This guidance is in contrast to the 2013 American College of Cardiology (ACC)/American Heart Association (AHA) guideline, which focuses on the use of fixed-dose, moderate- to high-intensity statin therapy to reduce LDL-C levels in patients at high CVD risk [8].

Like most guidelines, neither the NLA nor ACC/AHA guideline considers elevated TG to be a treatment target unless levels are very high $(\geq 500 \mathrm{mg} / \mathrm{dL})$. The NLA guideline highlights that in this case, TG lowering becomes the primary management goal, and the immediate use of a TG-lowering drug, including high-dose OM3FAs, is warranted [5]. Although the ACC/AHA guideline does not make any specific recommendations for the treatment of patients with very high TG levels, it does direct the reader to the 2011 AHA scientific statement on TG and CVD, which recommends the use of pharmacological therapy with a TG-lowering drug, including fibrates, niacin, or OM3FAs [28].

In the management of elevated TG levels, both the 2014 NLA guideline and the 2011 AHA scientific statement focus on intensive therapeutic lifestyle intervention, including a 5-10\% reduction in body weight, restriction of alcohol and sugar intake, and increased physical activity $[5,28]$. The NLA guideline also states that when TG levels are high (200-499 $\mathrm{mg} / \mathrm{dL}$ ), non-HDL-C remains the primary treatment target, and statins the first-line therapy choice. However, if non-HDL-C treatment goals $(<130 \mathrm{mg} /$ $\mathrm{dL}$ for low- to high-risk patients or $<100 \mathrm{mg} / \mathrm{dL}$ for veryhigh-risk patients) are not achieved with the maximum tolerated statin therapy, the guideline advocates the addition of a TG-lowering drug, such as OM3FAs, fibrates, or niacin, to statin therapy in patients with hypertriglyceridemia [5].

Like the 2014 NLA guideline, a number of other guidelines pertaining to the treatment and management of hypertriglyceridemia also recommend the use of TGlowering drugs (including high-dose OM3FAs), alone or in combination with statin therapy, in patients who continue to have elevated TG or non-HDL-C levels despite being at LDL-C treatment goal [31, 33, 34]. That being said, as mentioned previously, in 2016 the FDA withdrew the approval for extended release niacin and some fibrates when coadministered with statins [12].

\section{Mechanism of action of omega-3 fatty acids}

Although the TG-lowering ability of prescription OM3FAs is well established, the exact TG-lowering mechanisms of action are not completely understood. Results from preclinical and clinical studies suggest that OM3FAs decrease serum TG concentrations by reducing TG synthesis, reducing the incorporation of TG into VLDL, reducing TG secretion, and enhancing TG clearance from VLDL particles [35] (Fig. 1). It has been proposed that OM3FAs exert these TG-lowering effects via a number of mechanisms: (1) OM3FAs are thought to decrease hepatic

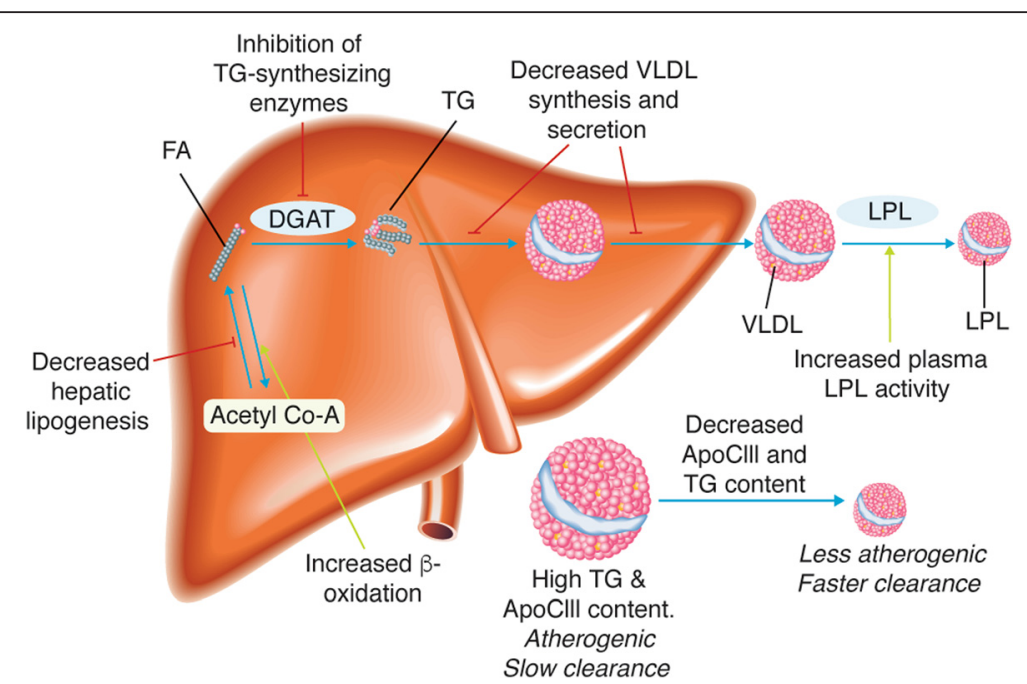

Fig. 1 Proposed mechanisms of action of prescription formulations of long-chain omega-3 fatty acids. ApoCIII apolipoprotein CIII, Acetyl Co-A acetyl coenzyme A, DGAT diglyceride acyltransferase; FA fatty acid, LPL lipoprotein lipase, TG triglyceride, VLDL very-low-density lipoprotein 
lipogenesis by suppressing the expression of sterol regulatory element-binding protein-1c. This, in turn, leads to decreased expression of cholesterol-, fatty acid-, and TGsynthesizing enzymes [36, 37]. (2) They are thought to increase the $\beta$-oxidation of fatty acids, resulting in a reduction in available substrate required for TG and VLDL synthesis [35]. (3) They are thought to inhibit key enzymes involved in hepatic TG synthesis, such as phosphatidic acid phosphatase and diacylglycerol acyltransferase [38]. (4) Finally, they have been shown to increase the expression of LPL, a key component of the TRL biosynthetic pathways, leading to increased TG removal from circulating VLDL and chylomicron particles [39, 40].

The primary components of OM3FA prescription formulations, EPA and DHA, have both been shown to reduce TG. However, they are known to have differing effects on LDL-C and HDL-C [41-43]. In a meta-analysis comparing the effects of DHA and EPA, in direct comparison studies, DHA was associated with a greater reduction in TG and a greater increase in LDL-C than EPA. DHA also raised HDL-C compared with placebo, whereas EPA did not [42]. Further research is needed to elucidate the mechanisms and significance of these differences [41-43].

OM3CAs have also been shown to reduce levels of apolipoprotein CIII (ApoCIII) [44]. ApoCIII is thought to contribute to the progression of atherosclerosis and CVD via a number of mechanisms, including the activation and enhancement of pro-inflammatory pathways [45]. It also inhibits the receptor-mediated uptake of TRL and their remnants, slowing their clearance rate, and promotes the formation of small dense LDL particles from VLDL $[44,45]$. Additionally, ApoCIII is a key contributor to hypertriglyceridemia, primarily due to its inhibitory actions on LPL. LPL hydrolyzes plasma TRL, producing free fatty acids, chylomicron remnants and intermediatedensity lipoproteins (IDL). Some IDL particles can also undergo further LPL-mediated hydrolysis to produce LDL [28]. It has been hypothesized that the differing effects of DHA and EPA on the lipid profile may be due to their differentiating effects on ApoCIII synthesis. DHA is thought to reduce ApoCIII synthesis by regulating a number of hepatic transcription factors, such as hepatic nuclear factor-4-alpha and forkhead box-O transcription factor O1. Therefore, DHA enhances the hydrolysis of VLDL, resulting in greater conversion to LDL, and the formation of larger, more buoyant LDL particles [43]. However, these effects are uncertain and warrant additional investigation.

In addition to their TG-lowering effects, OM3FA are thought to act on additional cardiometabolic risk factors, and have been shown to significantly decrease a number of inflammatory markers associated with atherosclerosis and CVD. Clinical studies have demonstrated that OM3CA and IPE decrease levels of lipoprotein-associated phospholipase A2 (Lp-PLA2) versus placebo, and IPE has been shown to decrease high-sensitivity $\mathrm{C}$-reactive protein [21, 23, 46]. Pre-clinical and clinical studies have also found that EPA and DHA exhibit antiarrhythmic and antioxidant effects [47, 48], improve endothelial function $[49,50]$, and promote a less atherogenic lipoprotein subfraction profile when administered in addition to statin therapy [51]. They have also been shown to decrease platelet activity biomarkers in comparison with placebo, regardless of concomitant aspirin and statin therapy use, and it is believed that they decrease platelet aggregation [52]. However, DHA is thought to display more potent anti-aggregatory effects than EPA $[49,50,53]$. In addition, DHA has been shown to lower blood pressure and heart rate [54-56], and seems to have a protective effect on cognitive decline [57]. Other studies have shown an inverse association between carotid intima-media thickness and OM3FA use, suggesting that OM3FA may protect against carotid atherosclerosis [58], with data indicating a decrease in plaque inflammation and an increase in plaque stability [59]. Despite these proposed cardioprotective mechanisms, to date, the effects of OM3FA-mediated TG lowering on cardiovascular outcomes and the incidence of pancreatitis have not yet been determined in large-scale clinical trials $[14,16,17,60]$.

Although the majority of research on the therapeutic potential of OM3FAs has focused on EPA and DHA, emerging research has also begun to elucidate the mechanisms of DPA. DPA levels are independently associated with a decreased risk of myocardial infarction and coronary heart disease $[61,62]$, and low levels of DPA have also been shown to be associated with lipid-rich plaques and peripheral arterial disease [63, 64]. Studies have demonstrated that EPA, DHA, and DPA dose-dependently inhibit platelet aggregation. However, DPA was shown to be a more potent platelet inhibitor than EPA and DHA [65]. Like DHA and EPA, DPA has also been shown to reduce the expression of inflammatory genes [66].

As the TG-lowering mechanism of action of long-chain OM3FAs differs from that of other lipid-lowering drugs, such as statins, they can potentially provide complementary benefits on the lipid profile when administered in combination [35]. This is corroborated by the fact that the level of TG lowering achieved with OM3FAs provides incremental reductions in TG levels when added to statin therapy $[20,22,24,67]$.

\section{Bioavailability}

Absorption of DHA and EPA has been shown to vary between formulations. OM3CA have a 4-fold greater bioavailability (area under the plasma concentration-time curve from zero to the last measurable concentration $\left.\left[\mathrm{AUC}_{(0-\mathrm{t})}\right]\right)$ for both EPA and DHA during low fatconsumption periods, compared with that of OM3FA ethyl 
esters [68]. The absorption of OM3FA ethyl esters (OM3EE and IPE) requires hydrolysis with pancreatic lipase [69, 70], and as pancreatic lipase levels are dependent on the quantity and the type of lipids ingested, the absorption of OM3FA ethyl esters is thought to be highly dependent on meal fat content [71, 72]. In contrast, OM3FAs in the free fatty acid form, found in OM3CA, are not dependent on pancreatic lipase hydrolysis. Therefore, the bioavailability of EPA and DHA from this formulation is less dependent on meal fat content than OM3FA ethyl esters [68]. In one study $(n=54)$, under low-fat conditions, $59 \%$ of subjects dosed with OM3CA maintained an $\mathrm{AUC}_{(0-\mathrm{t})}$ for $\mathrm{EPA}$ and DHA of $\geq 50 \%$ of the respective $\mathrm{AUC}_{(0-\mathrm{t})}$ observed in highfat conditions, compared with only $6 \%$ of subjects dosed with OM3EE. This may confer a potential therapeutic advantage, as current guidelines recommend that patients with severe hypertriglyceridemia follow a very-low-fat diet $[5,28]$. This increased bioavailability, particularly during low fat consumption, may also allow greater flexibility with regard to dosing schedule. OM3CA have been approved to effectively lower TG levels at doses of $2 \mathrm{~g} /$ day or $4 \mathrm{~g} /$ day, in a once-daily dosing regimen without regard to meals [22].

\section{Efficacy of omega-3 fatty acid formulations}

The effects of the three OM3FA prescription formulations on lipid parameters in patients with severe hypertriglyceridemia are summarized in Table 2. These data are reported in the US prescribing information for OM3EE (Lovaza) [14], IPE (Vascepa) [16], and OM3CA (Epanova) [17], which each summarize the results from the respective pivotal, randomized, double-blind, placebo-controlled trials conducted in patients with baseline TG levels of $500-2000 \mathrm{mg} / \mathrm{dL}[18,19,21,23]$. It is important to note that the type of placebo used differs among these clinical trials, and each placebo has differing effects on TG. The olive oil comparator used in the OM3CA trial substantially decreased TG levels, whereas the corn oil and mineral oil used in the OM3EE and IPE trials increased TG levels. In patients with TG levels $>500 \mathrm{mg} / \mathrm{dL}$, the TG reductions observed with all prescription formulations, at doses of $4 \mathrm{~g} /$ day, were statistically significant compared with placebo, thus allowing the US FDA to approve these formulations for adults with severe hypertriglyceridemia. As might be expected, higher OM3FA doses and higher baseline TG levels are associated with greater percentage TG reductions [73] (Fig. 2). Reductions in VLDL-C levels versus placebo were also shown to be statistically significant.

It should be noted that there appears to be a tendency for DHA-containing formulations (OM3CA and OM3EE) to increase LDL-C versus baseline. However, importantly, this is not associated with an accompanying increase in non-HDL-C or ApoB, and as mentioned earlier, nonHDL-C levels are thought to provide a better indication of CVD risk than LDL-C levels. This is particularly the case for patients with hypertriglyceridemia, who often have low levels of LDL-C [5, 34]. Additionally, unlike IPE, DHAcontaining formulations increase HDL-C levels. However, the clinical relevance of increasing HDL-C using any pharmacologic agent remains unclear.

Similar effects on lipid parameters are observed in statin-treated patients with high TG levels $(\geq 200 \mathrm{mg} / \mathrm{dL}$ and $<500 \mathrm{mg} / \mathrm{dL}$ ) (Table 3) [20, 22, 24]. All prescription formulations of OM3FAs at a dose of $4 \mathrm{~g}$ /day were shown to significantly reduce TG, VLDL-C, non-HDL-C, and ApoB levels in this patient population. However, in contrast to patients with severe hypertriglyceridemia (TG $\geq 500 \mathrm{mg} / \mathrm{dL}$ ), no increase in LDL-C was observed with any of the formulations. This is likely due to the fact that these patients had lower baseline TG levels and were also receiving statin therapy. The levels of TG reduction observed with varying doses of the three OM3FA formulations in patients with severe hypertriglyceridemia and high levels of TG are shown in Fig. 2a and b.

To date, the effect of any of the prescription OM3FA formulations on pancreatitis has not been determined. Furthermore, no large-scale, randomized clinical trials have provided clear evidence for the association between TG lowering and CVD risk reduction [14, 16, 17, 60]. Two large-scale, multinational cardiovascular outcomes studies (the Reduction of Cardiovascular Events with EPA - Intervention Trial [REDUCE-IT; NCT01492361] [74] and STatin Residual risk reduction with EpaNova in hiGh cardiovascular risk paTients with Hypertriglyceridemia [STRENGTH; NCT02104817] [75]) are currently under way to address this question. These trials aim to evaluate the reduction in residual risk of statin-treated patients with high TGs treated with OM3FA. The trials will examine the safety and efficacy of prescription strength longchain OM3FAs in combination with statin therapy in high-risk patients with hypertriglyceridemia, defined as TG up to $500 \mathrm{mg} / \mathrm{dL}$.

\section{Omega-3 fatty acids in pediatric populations}

The process of atherosclerosis can begin in early childhood, particularly in the presence of known cardiovascular risk factors, such as obesity, hypertension, and diabetes mellitus [76]. Studies have shown that omega-3 fatty acid supplementation can have beneficial effects on preclinical atherosclerosis markers in children with cardiovascular risk factors, including the prevention of carotid artery intima-media thickness and increased artery flow-mediated vasodilation [50, 77]. In addition, dietary omega-3 fatty acid supplementation in infancy has been associated with lower blood pressure in later childhood [78, 79]. Therefore, it has been suggested that dietary supplementation of omega- 3 fatty acids in children may improve future cardiovascular outcomes [80]. 
Table 2 Change in lipid parameters observed with omega-3 carboxylic acids, omega-3 ethyl esters, and icosapent ethyl in patients with severe hypertriglyceridemia (triglyceride level $\geq 500 \mathrm{mg} / \mathrm{dL}$ )

\begin{tabular}{|c|c|c|c|c|c|c|c|}
\hline \multirow[b]{2}{*}{ Parameter } & \multicolumn{3}{|c|}{ OM3CA (Epanova) [17] } & \multicolumn{2}{|c|}{ OM3EE (Lovaza) [14] } & \multicolumn{2}{|l|}{ IPE (Vascepa) [16] } \\
\hline & $\begin{array}{l}\text { Placebo (olive oil) } \\
(n=100)\end{array}$ & $\begin{array}{l}\text { OM3CA } 2 \text { g/day } \\
(n=100)\end{array}$ & $\begin{array}{l}\text { OM3CA } 4 \text { g/day } \\
(n=99)\end{array}$ & $\begin{array}{l}\text { Placebo (corn oil) } \\
(n=42)\end{array}$ & $\begin{array}{l}\text { OM3EE } 4 \text { g/day } \\
(n=42)\end{array}$ & $\begin{array}{l}\text { Placebo (mineral oil) } \\
(n=75)\end{array}$ & $\begin{array}{l}\text { IPE } 4 \mathrm{~g} / \text { day } \\
(n=76)\end{array}$ \\
\hline \multicolumn{8}{|l|}{$\overline{\mathrm{TG}}$} \\
\hline Median BL, mg/dL & 682 & 717 & 655 & 788 & 816 & 703 & 680 \\
\hline $\begin{array}{l}\text { Median percentage } \\
\text { change from BL, \% }\end{array}$ & -10 & -25 & -31 & 7 & -45 & 10 & -27 \\
\hline Difference $^{\ddagger}$ & - & $-16^{* *}$ & $-21^{* * *}$ & - & -52 & - & $-33^{* * *}$ \\
\hline \multicolumn{8}{|l|}{ Non-HDL-C } \\
\hline Median BL, mg/dL & 215 & 205 & 225 & 292 & 271 & 229 & 225 \\
\hline $\begin{array}{l}\text { Median percentage } \\
\text { change from BL, \% }\end{array}$ & -1 & -8 & -8 & -4 & -14 & 8 & -8 \\
\hline Difference $^{\ddagger}$ & - & $-7^{*}$ & $-10^{* *}$ & - & -10 & - & -18 \\
\hline \multicolumn{8}{|l|}{ HDL-C } \\
\hline Median BL, mg/dL & 29 & 27 & 29 & 24 & 22 & 27 & 27 \\
\hline $\begin{array}{l}\text { Median percentage } \\
\text { change form BL, } \%\end{array}$ & 2 & 7 & 5 & 0 & 9 & 0 & -4 \\
\hline Difference $^{\ddagger}$ & - & $5^{+}$ & $4^{+}$ & - & 9 & - & -4 \\
\hline \multicolumn{8}{|l|}{ Total cholesterol } \\
\hline Median BL, mg/dL & 246 & 241 & 254 & 314 & 296 & 256 & 254 \\
\hline $\begin{array}{l}\text { Median percentage } \\
\text { change from } B L, \%\end{array}$ & 0 & -6 & -6 & -2 & -10 & 8 & -7 \\
\hline Difference $^{\ddagger}$ & - & -6 & -9 & - & -8 & - & -16 \\
\hline \multicolumn{8}{|l|}{ VLDL-C } \\
\hline Median BL, mg/dL & 125 & 123 & 126 & 175 & 175 & 124 & 123 \\
\hline $\begin{array}{l}\text { Median percentage } \\
\text { change from } B \mathrm{~L}, \%\end{array}$ & -11 & -25 & -35 & -1 & -42 & 14 & -20 \\
\hline Difference $^{\ddagger}$ & - & -14 & -21 & - & -41 & - & $-29^{*}$ \\
\hline \multicolumn{8}{|l|}{ LDL-C } \\
\hline Median BL, mg/dL & 78 & 77 & 90 & 108 & 89 & 86 & 91 \\
\hline $\begin{array}{l}\text { Median percentage } \\
\text { change from } B L, \%\end{array}$ & 10 & 21 & 26 & -5 & 45 & -3 & -5 \\
\hline Difference $e^{\ddagger}$ & - & 13 & 15 & - & 49 & - & -2 \\
\hline \multicolumn{8}{|l|}{ ApoB } \\
\hline Median BL, mg/dL & 110 & 114 & 118 & ND & ND & 118 & 121 \\
\hline $\begin{array}{l}\text { Median percentage } \\
\text { change from } B L, \%\end{array}$ & 2 & 6 & 6 & ND & ND & 4 & -4 \\
\hline Difference $^{\ddagger}$ & - & 3 & 2 & - & ND & - & $-9^{*}$ \\
\hline
\end{tabular}

$P$-values from Wilcoxon rank sum test: ${ }^{*} P<0.05 ;{ }^{* *} P<0.01 ;{ }^{* *} P<0.001 ;{ }^{\dagger}$ not significant. Testing for statistical significance was performed for OM3CA (TG, non-HDL-C and HDL-C) and IPE (TG, VLDL-C, and ApoB) only. No statistical analysis was presented for OM3EE

${ }^{\ddagger}$ Difference for OM3CA and IPE = median of [omega-3 fatty acid formulation \% change - placebo \% change]

(Hodges-Lehmann Estimate); Difference for OM3EE = OM3EE median \% change - placebo median \% change

The median placebo-corrected \% change in lipid parameters reported for Omtryg, the generic form of Lovaza, are as follows: TG $=-12 \%$,

non-HDL-C $=-9 \%, \mathrm{HDL}-\mathrm{C}=4 \%, \mathrm{TC}=-7 \%$, VLDL-C $=-29 \%$, and LDL-C $=25 \%[15]$

$A p o B$ apolipoprotein B, BL baseline, HDL-C high-density lipoprotein cholesterol, IPE icosapent ethyl, LDL-C low-density lipoprotein cholesterol,

$N D$ not described, OM3CA omega-3 carboxylic acids, OM3EE omega-3 ethyl esters, TG triglyceride, VLDL-C very-low-density lipoprotein cholesterol

\section{Safety}

Prescription formulations of OM3FAs are generally well tolerated, with frequencies of treatment discontinuation similar between the OM3FA groups and placebo groups
[81]. The most common adverse events associated with OM3FAs are gastrointestinal in nature (including eructation, nausea, diarrhea, and other mild gastrointestinal disturbances), and have been shown to occur in up to 

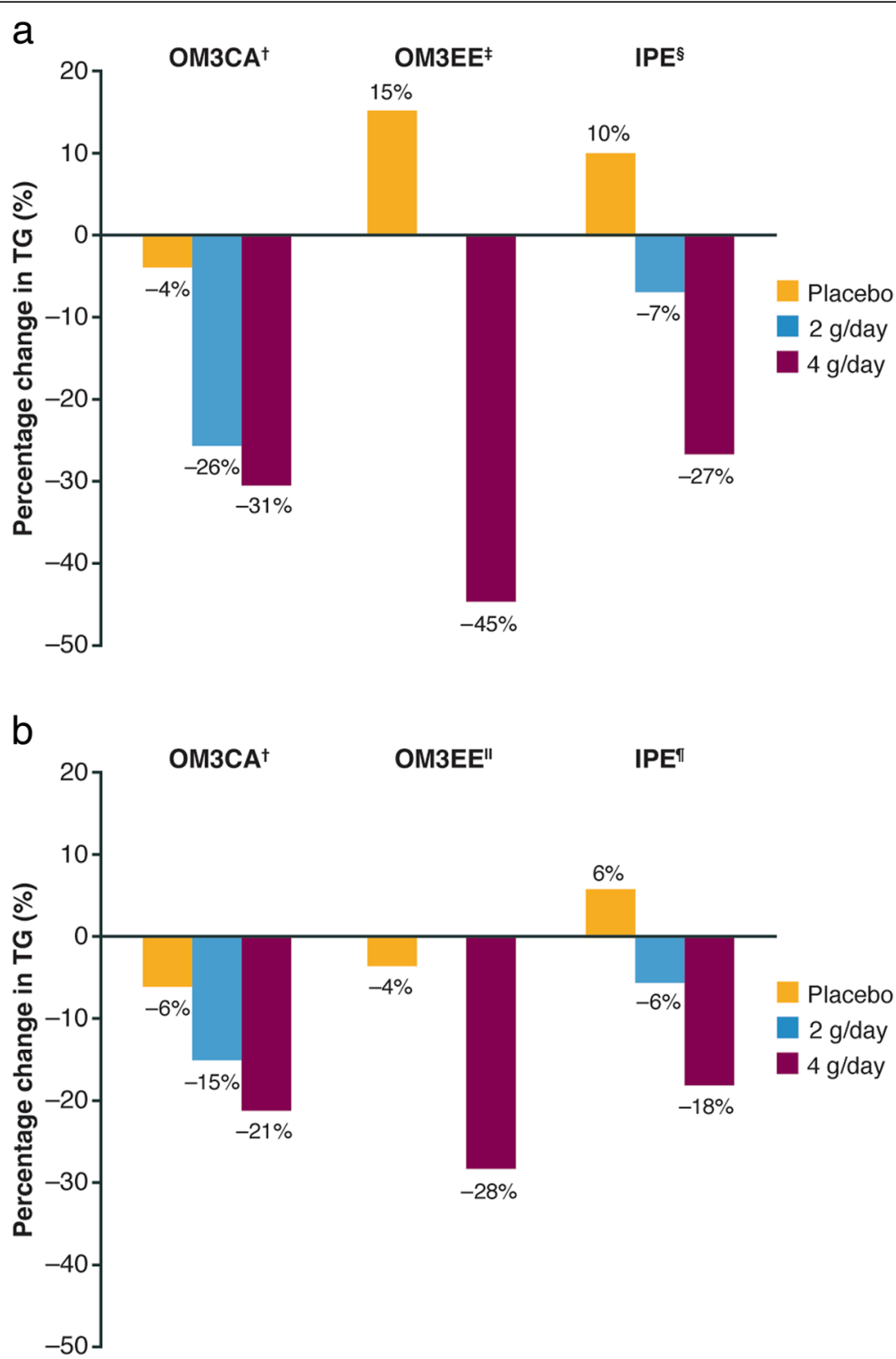

Fig. 2 TG reduction observed with varying doses of omega-3 carboxylic acids, omega-3 ethyl esters, and icosapent ethyl in (a) patients with severe hypertriglyceridemia (TG $\geq 500 \mathrm{mg} / \mathrm{dL}$ ) $[14,16,17]$ and (b) statin-treated patients with high baseline TG levels (TG level $\geq 200 \mathrm{mg} / \mathrm{dL}$ and $<500 \mathrm{mg} / \mathrm{dL}$ ) $[20,21,24]$ Data not available for OM3EE at $2 \mathrm{~g} /$ day. OM3CA = Percentage change from baseline expressed as least-squares geometric mean; OM3EE = percentage change from baseline expressed as geometric mean; IPE = percentage change from baseline expressed as median. ${ }^{\dagger}$ Placebo used = olive oil;

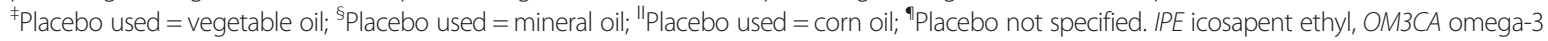
carboxylic acids, OM3EE omega-3 ethyl esters, TG triglyceride

$27 \%$ of patients at doses of $4 \mathrm{~g} /$ day $[18,21,23]$. The most common adverse events reported in the US prescribing information for each formulation are summarized in Table 4. Studies have shown that OM3FAs do not affect liver function [18], and do not have any known clinically significant drug-drug interactions with other commonly used lipid-modifying drugs, such as statins [82-84]. In contrast to a number of other TG-lowering drugs, studies have also shown that adverse events detected in patients receiving combination therapy with OM3FA ethyl esters and statins were similar to those detected in patients receiving statin monotherapy $[20,85,86]$. This is particularly advantageous when statin users with a history of common adverse events (e.g. myalgia, elevated hepatic transaminases) require combination therapy with a TGlowering drug. Additionally, although OM3FAs have been shown to have the potential for antithrombotic effects, they have been shown not to increase clinical bleeding, even in patients receiving warfarin or antiplatelet drugs, including aspirin [87-90]. 
Table 3 Change in lipid parameters observed with omega-3 carboxylic acids, omega-3 ethyl esters, and icosapent ethyl in statin-treated patients with high triglyceride levels (triglyceride level $\geq 200 \mathrm{mg} / \mathrm{dL}$ and $<500 \mathrm{mg} / \mathrm{dL}$ )

\begin{tabular}{|c|c|c|c|c|c|c|c|c|}
\hline \multirow[b]{2}{*}{ Parameter } & \multicolumn{3}{|c|}{ OM3CA (Epanova) [22] } & \multicolumn{2}{|l|}{ OM3EE (Lovaza) [20] } & \multicolumn{3}{|l|}{ IPE (Vascepa) [24] } \\
\hline & $\begin{array}{l}\text { Statin }^{\dagger}+\text { olive oil } \\
(n=215)\end{array}$ & $\begin{array}{l}\text { Statin }^{\dagger}+\text { OM3CA } \\
2 \mathrm{~g} / \text { day }(n=215)\end{array}$ & $\begin{array}{l}\text { Statin }^{\dagger}+\text { OM3CA } \\
4 \mathrm{~g} / \text { day }(n=215)\end{array}$ & $\begin{array}{l}\text { Simvastatin } \\
40 \mathrm{mg}+\text { vegetable } \\
\text { oil }(n=132)\end{array}$ & $\begin{array}{l}\text { Simvastatin } \\
40 \mathrm{mg}+\text { OM3EE } \\
4 \mathrm{~g} / \text { day }(n=122)\end{array}$ & $\begin{array}{l}\text { Statin }^{\ddagger}+\text { placebo }^{\S} \\
(n=277)\end{array}$ & $\begin{array}{l}\text { Statin }^{\ddagger}+\text { IPE } \\
2 \text { g/day } \\
(n=234)\end{array}$ & $\begin{array}{l}\text { Statin }^{\ddagger}+\text { IPE } \\
4 \mathrm{~g} / \text { day } \\
(n=226)\end{array}$ \\
\hline \multicolumn{9}{|l|}{ TG } \\
\hline $\mathrm{BL}, \mathrm{mg} / \mathrm{dL}$ & 280 & 284 & 287 & 286.7 & 282.0 & 259.0 & 254 & 264.8 \\
\hline$\%$ change & -5.9 & $-14.6^{* * *}$ & $-20.6^{* * *}$ & -3.5 & $-28.2^{* * *}$ & 5.9 & $-5.6^{* *}$ & $-17.5^{* * *}$ \\
\hline \multicolumn{9}{|l|}{ Non-HDL-C } \\
\hline $\mathrm{BL}, \mathrm{mg} / \mathrm{dL}$ & 135 & 140 & 139 & 141.3 & 135.8 & 128 & 128 & 128 \\
\hline$\%$ change & -0.9 & $-3.9^{*}$ & $-6.9^{* * *}$ & -1.5 & $-7.9^{* * *}$ & 9.8 & 2.4 & $-5.0^{* * *}$ \\
\hline \multicolumn{9}{|l|}{$\mathrm{HDL}-\mathrm{C}$} \\
\hline $\mathrm{BL}, \mathrm{mg} / \mathrm{dL}$ & 38.8 & 38.7 & 38.8 & 44.7 & 47.3 & 39.0 & 38.0 & 37.0 \\
\hline$\%$ change & 2.2 & 2.6 & 3.3 & -1.1 & $4.1^{* * *}$ & 4.8 & 0.0 & $-1.0^{* *}$ \\
\hline \multicolumn{9}{|c|}{ Total cholesterol } \\
\hline $\mathrm{BL}, \mathrm{mg} / \mathrm{dL}$ & 174 & 179 & 178 & 186.0 & 183.1 & 168.0 & 169 & 167 \\
\hline$\%$ change & 0.5 & $-1.7^{*}$ & $-3.8^{* * *}$ & -1.5 & $-4.7^{* *}$ & 9.1 & 2.1 & $-3.2^{* * *}$ \\
\hline \multicolumn{9}{|l|}{ VLDL-C } \\
\hline $\mathrm{BL}, \mathrm{mg} / \mathrm{dL}$ & 45.7 & 46.9 & 47.2 & 53.2 & 52.1 & 42.0 & 43.0 & 44.0 \\
\hline$\%$ change & -5.9 & $-14.3^{* *}$ & $-21.5^{* * *}$ & -4.8 & $-23.8^{* * *}$ & 15.0 & 1.6 & $-12.1^{* * *}$ \\
\hline \multicolumn{9}{|l|}{ LDL-C } \\
\hline $\mathrm{BL}, \mathrm{mg} / \mathrm{dL}$ & 91.7 & 92.3 & 93.6 & 92.3 & 89.2 & 84.0 & 82.0 & 82.0 \\
\hline$\%$ change & 1.1 & $4.6^{*}$ & 1.3 & -1.9 & 3.4 & 8.8 & 2.4 & $1.5^{* *}$ \\
\hline \multicolumn{9}{|l|}{ ApoB } \\
\hline $\mathrm{BL}, \mathrm{mg} / \mathrm{dL}$ & 93.8 & 94.5 & 95.9 & 86.8 & 85.0 & 91.0 & 91.0 & 93.0 \\
\hline$\%$ change & 0.3 & 0.7 & $-2.1^{*}$ & -1.2 & $-3.8^{*}$ & 7.1 & 1.6 & $-2.2^{* * *}$ \\
\hline
\end{tabular}

For IPE, data are presented as median; for OM3CA, data are presented as least-squares mean; for OM3EE, data are presented as geometric mean. $P$-values versus placebo: ${ }^{*} P<0.05 ;{ }^{*} P<0.01$; ${ }^{* * *} P<0.001$. ${ }^{\dagger}$ Statins

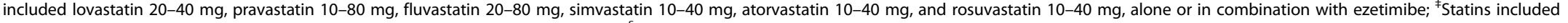
simvastatin, atorvastatin, and rosuvastatin, alone or in combination with ezetimibe. ${ }^{5}$ Placebo not specified

$A p o B$ apolipoprotein B, BL baseline, HDL-C high-density lipoprotein cholesterol, IPE icosapent ethyl, LDL-C low-density lipoprotein cholesterol, OM3CA omega-3 carboxylic acids, OM3EE omega-3 ethyl esters,

$T G$ triglyceride, VLDL-C very-low-density lipoprotein cholesterol 
Table 4 Summary of adverse events observed with omega-3 carboxylic acids [17], omega-3 ethyl esters [14], and icosapent ethyl [16] in pooled placebo-controlled trials conducted in patients with hypertriglyceridemia, based on prescribing information for each formulation

\begin{tabular}{|c|c|c|c|c|c|c|c|}
\hline \multirow[t]{3}{*}{ Adverse event, \% } & \multicolumn{3}{|l|}{ OMЗСА } & \multicolumn{2}{|l|}{ OM3EE } & \multicolumn{2}{|l|}{ IPE } \\
\hline & \multicolumn{3}{|c|}{ Adverse events occurring at an incidence $\geq 3 \%$} & \multicolumn{2}{|c|}{$\begin{array}{l}\text { Adverse events occurring } \\
\text { at an incidence } \geq 3 \%\end{array}$} & \multicolumn{2}{|c|}{$\begin{array}{l}\text { Adverse events occurring } \\
\text { at an incidence }>2 \%\end{array}$} \\
\hline & $\begin{array}{l}\text { Placebo (olive oil) } \\
(n=314)\end{array}$ & $\begin{array}{l}\text { OM3CA } 2 \text { g/day } \\
(n=315)\end{array}$ & $\begin{array}{l}\text { OM3CA } 4 \text { g/day } \\
(n=630)\end{array}$ & $\begin{array}{l}\text { Placebo (corn oil) } \\
(n=370)\end{array}$ & $\begin{array}{l}\text { OM3EE } \\
(n=655)\end{array}$ & $\begin{array}{l}\text { Placebo (mineral oil) } \\
(n=309)\end{array}$ & IPE $(n=622)$ \\
\hline Diarrhea & 2 & 7 & 15 & - & - & - & - \\
\hline Nausea & 1 & 4 & 6 & - & - & - & - \\
\hline Abdominal pain or discomfort & 2 & 3 & 5 & - & - & - & - \\
\hline Eructation & $<1$ & 3 & 3 & 1 & 4 & - & - \\
\hline Dyspepsia & - & - & - & 2 & 3 & - & - \\
\hline Taste perversion & - & - & - & $<1$ & 4 & - & - \\
\hline Arthralgia & - & - & - & - & - & 1 & 2 \\
\hline
\end{tabular}

IPE icosapent ethyl, OM3CA omega-3 carboxylic acids, OM3EE omega-3 ethyl esters

It is not known whether patients with allergies to fish and/or shellfish are at an increased risk of allergic reaction to OM3FAs, and so these formulations should be used with caution in patients with known hypersensitivity to fish and/or shellfish [14, 16, 17].

\section{Dietary-supplement omega-3 fatty acids}

Dietary-supplement OM3FAs are also widely utilized and are among the most popular dietary supplements worldwide [91]. However, dietary supplements are not subject to rigorous regulations required for prescription drugs. Consequently, the EPA and DHA content of dietary supplements may be inconsistent [25-27]. Due to an early evaluation study, practitioners typically view supplemental OM3FAs as adequate and reliable [92]. However, a more recent analysis of individual fish oil supplements found that they contain an inadequate dose of EPA and DHA. On average, they contained only $68 \%$ of the claimed EPA and DHA content. The same analysis also found that the majority of supplements exceeded recommended levels of oxidation markers [26]. As the OM3FAs undergo oxidation, the concentration of EPA and DHA decreases, suggesting reduced efficacy. One study demonstrated that a median intake of 11 dietary fish oil supplement servings/ day was required to achieve an FDA-approved dose of $3.4 \mathrm{~g} /$ day of OM3FAs $[27,93]$. This study also found that dietary-supplement OM3FAs contain other fats and cholesterol, and that the fat and cholesterol content varies widely among products [27]. In addition, as the EPA and DHA content of dietary supplements varies among products, this may cause confusion for patients and practitioners. This is likely to result in inaccurate dosing that may potentially be inadequate to effectively lower TG in patients with hypertriglyceridemia.

Dietary omega-3 fatty acid intake has also been shown to play a role in cardiovascular risk reduction, with modest fish consumption (1-2 servings per week, particularly species high in EPA and DHA) associated with reduced risk of coronary death and total mortality [94]. Consequently, the AHA recommends including at least two servings of fish (preferably oily fish) per week [95]. In addition, it has been suggested that omega-3-enriched supplements (nutraceuticals) and functional foods (e.g. EPA- and DHA-enriched food products) may offer the possibility of increased EPA and DHA consumption $[96,97]$. However, the benefits of nutraceutical products remain unclear, and robust clinical trials are required to establish their exact role in cardiovascular risk reduction [97].

\section{Conclusion}

In severe hypertriglyceridemia ( $\mathrm{TG} \geq 500 \mathrm{mg} / \mathrm{dL}$ ), guidelines advocate the immediate use of a TG-lowering drug to reduce the risk of pancreatitis. In patients with high TG levels ( $\geq 200$ to $<500 \mathrm{mg} / \mathrm{dL}$ ), some guidelines also recommend the use of TG-lowering drugs if elevated TG or non-HDL-C levels persist despite lifestyle intervention and statin therapy. Available TG-lowering drugs include fibrates, niacin, and OM3FAs. Unlike fibrates and niacin, OM3FAs do not have any known, clinically significant drug-drug interactions with other lipid-modifying therapies (such as statins) and do not affect liver function. In addition, as their mechanisms of action differ from those of other lipid-lowering drugs, they can potentially provide complementary benefits when administered as a combination therapy with statins.

All formulations have been shown to significantly reduce TG levels, and despite some differences in formulation, they appear to have similar efficacy. However, OM3FAs have been shown to differ in their effects on individual lipid parameters, their bioavailability, and the impact of fat content of meals on absorption. Although dietary supplements are available and widely utilized, 
they are not subject to the rigorous regulations required for prescription drugs, and therefore, their EPA and DHA content may be inconsistent and often may not meet label claims. All three prescription formulations of OM3FAs currently approved for use in the US appear to be generally well tolerated and effective in reducing TG levels in patients with hypertriglyceridemia.

\begin{abstract}
Abbreviations
ACC, American College of Cardiology; AHA, American Heart Association; Apo, apolioprotein; $A \cup C_{(0-t)}$ area under the plasma concentration-time curve from zero to the last measurable concentration; CVD, cardiovascular disease; DHA, docosahexaenoic acid; DPA, docosapentaenoic acid; EPA, eicosapentaenoic acid; FDA, Food and Drug Administration; HDL-C, high-density lipoprotein cholesterol; IDL, intermediate-density lipoproteins; IPE, icosapent ethyl; LDL-C, low-density lipoprotein cholesterol; LPL, lipoprotein lipase; NLA, National Lipid Association; OM3CA, Omega-3 carboxylic acids; OM3EE, omega-3 fatty acid ethyl esters; OM3FA, omega-3 fatty acids; TG, triglyceride; TRL, TG-rich lipoproteins; US, United States; $V L D L$, very-low-density lipoproteins
\end{abstract}

\section{Acknowledgments}

Medical writing support was provided by Alex Mellors, Prime Medica, Knutsford, Cheshire, UK, funded by AstraZeneca. The opinions, conclusions, and interpretation of the data are the responsibility of the authors.

\section{Authors' contributions}

All authors made substantial contributions to the conception of the review, were involved in drafting and critically revising the review for important intellectual content, and have given final approval of and have agreed to be accountable for all aspects of the review.

\section{Competing interests}

James Backes has participated in a Speakers Bureau for AstraZeneca. Deborah Anzalone and Julia Catini are employees of AstraZeneca. Daniel Hilleman has participated in a Speakers Bureau for Bristol-Myers Squibb and Novartis.

\section{Author details}

'Atherosclerosis and LDL-Apheresis Center, School of Pharmacy, University of Kansas, 3901 Rainbow Boulevard, Kansas City, KS 66160, USA. ${ }^{2}$ AstraZeneca, Wilmington, DE, USA. ${ }^{3}$ Creighton University, Omaha, NE, USA.

\section{Received: 5 March 2016 Accepted: 8 July 2016}

Published online: 22 July 2016

\section{References}

1. Carroll M, Kit B, Lacher D. Trends in elevated triglyceride in adults: United States, 2001-2012. NCHS Data Brief. 2015;198:1-8.

2. Miller M, Cannon CP, Murphy SA, Qin J, Ray KK, Braunwald E. Impact of triglyceride levels beyond low-density lipoprotein cholesterol after acute coronary syndrome in the PROVE IT-TIMI 22 trial. J Am Coll Cardiol. 2008;51:724-30.

3. Schwartz GG, Abt M, Bao W, DeMicco D, Kallend D, Miller M, Mundl H, Olsson AG. Fasting triglycerides predict recurrent ischemic events in patients with acute coronary syndrome treated with statins. J Am Coll Cardiol. 2015:65:2267-75.

4. Rosenson RS, Davidson MH, Hirsh BJ, Kathiresan S, Gaudet D. Genetics and causality of triglyceride-rich lipoproteins in atherosclerotic cardiovascular disease. J Am Coll Cardiol. 2014;64:2525-40.

5. Jacobson TA, Ito MK, Maki KC, Orringer CE, Bays HE, Jones PH, McKenney JM, Grundy SM, Gill EA, Wild RA, et al. National Lipid Association recommendations for patient-centered management of dyslipidemia: part 1 - executive summary. J Clin Lipidol. 2014;8:473-88.

6. Kota SK, Kota SK, Jammula S, Krishna SV, Modi KD. Hypertriglyceridemiainduced recurrent acute pancreatitis: a case-based review. Indian J Endocrinol Metab. 2012;16:141-3.

7. Hegele RA, Ginsberg HN, Chapman MJ, Nordestgaard BG, Kuivenhoven JA, Averna M, Boren J, Bruckert E, Catapano AL, Descamps OS, et al. The polygenic nature of hypertriglyceridaemia: implications for definition, diagnosis, and management. Lancet Diabetes Endocrinol. 2014;2:655-66.

8. Stone NJ, Robinson JG, Lichtenstein AH, Bairey Merz CN, Blum CB, Eckel RH, Goldberg AC, Gordon D, Levy D, Lloyd-Jones DM, et al. 2013 ACC/AHA guideline on the treatment of blood cholesterol to reduce atherosclerotic cardiovascular risk in adults: a report of the American College of Cardiology/ American Heart Association Task Force on Practice Guidelines. J Am Coll Cardiol. 2014;63:2889-934.

9. AstraZeneca. Crestor US prescribing information. Available at: http://www1. astrazeneca-us.com/pi/crestor.pdf. Accessed 24 Nov 2015.

10. Davidson MH, Armani A, McKenney JM, Jacobson TA. Safety considerations with fibrate therapy. Am J Cardiol. 2007;99:3c-18c.

11. Guyton JR, Bays HE. Safety considerations with niacin therapy. Am J Cardiol. 2007;99:22c-31c.

12. Food and Drug Administration. Withdrawal of Approval of Indications Related to the Coadministration With Statins in Applications for Niacin Extended-Release Tablets and Fenofibric Acid Delayed-Release Capsules. Available at: https://www.federalregister.gov/articles/2016/04/18/201608887/abbvie-inc-et-al-withdrawal-of-approval-of-indications-related-to-thecoadministration-with-statins\#h-11. Accessed: 5 Sep 2016.

13. Ito MK. Long-chain omega-3 fatty acids, fibrates and niacin as therapeutic options in the treatment of hypertriglyceridemia: a review of the literature. Atherosclerosis. 2015;242:647-56.

14. GlaxoSmithKline. Lovaza prescribing information. Available at: https://www. gsksource.com/gskprm/htdocs/documents/LOVAZA-PI-PIL.PDF. Accessed: 24 Nov 2015

15. Trygg Pharma. Omtryg prescribing information. Available at: http://www. accessdata.fda.gov/drugsatfda_docs/label/2014/204977s000lbl.pdf. Accessed: 24 Nov 2015

16. Amarin Corporation. Vascepa prescibing information. Available at: www. vascepa.com/full-prescribing-information.pdf. Accessed: 24 Nov 2015

17. AstraZeneca. Epanova prescribing information. Available at: http://www1. astrazeneca-us.com/pi/epanova.pdf. Accessed: 24 Nov 2015

18. Harris WS, Ginsberg HN, Arunakul N, Shachter NS, Windsor SL, Adams M, Berglund L, Osmundsen K. Safety and efficacy of Omacor in severe hypertriglyceridemia. J Cardiovasc Risk. 1997;4:385-91.

19. Pownall HJ, Brauchi D, Kilinc C, Osmundsen K, Pao Q, Payton-Ross C, Gotto AJ, Ballantyne CM. Correlation of serum triglyceride and its reduction by omega-3 fatty acids with lipid transfer activity and the neutral lipid compositions of high-density and low-density lipoproteins. Atherosclerosis. 1999;143:285-97.

20. Davidson MH, Stein EA, Bays HE, Maki KC, Doyle RT, Shalwitz RA, Ballantyne CM, Ginsberg HN. Efficacy and tolerability of adding prescription omega-3 fatty acids $4 \mathrm{~g} / \mathrm{d}$ to simvastatin $40 \mathrm{mg} / \mathrm{d}$ in hypertriglyceridemic patients: an 8-week, randomized, double-blind, placebo-controlled study. Clin Ther. 2007:29:1354-67.

21. Kastelein JJ, Maki KC, Susekov A, Ezhov M, Nordestgaard BG, Machielse BN, Kling D, Davidson MH. Omega-3 free fatty acids for the treatment of severe hypertriglyceridemia: the EpanoVa fOr Lowering Very high triglyceridEs (EVOLVE) trial. J Clin Lipidol. 2014:8:94-106.

22. Maki KC, Orloff DG, Nicholls SJ, Dunbar RL, Roth EM, Curcio D, Johnson J, Kling $\mathrm{D}$, Davidson $\mathrm{MH}$. A highly bioavailable omega-3 free fatty acid formulation improves the cardiovascular risk profile in high-risk, statin-treated patients with residual hypertriglyceridemia (the ESPRIT trial). Clin Ther. 2013;35:1400-11.

23. Bays HE, Ballantyne CM, Kastelein JJ, Isaacsohn JL, Braeckman RA, Soni PN. Eicosapentaenoic acid ethyl ester (AMR101) therapy in patients with very high triglyceride levels (from the Multi-center, plAcebo-controlled, Randomized, double-blINd, 12-week study with an open-label Extension [MARINE] trial). Am J Cardiol. 2011;108:682-90.

24. Ballantyne CM, Bays HE, Kastelein JJ, Stein E, Isaacsohn JL, Braeckman RA, Soni PN. Efficacy and safety of eicosapentaenoic acid ethyl ester (AMR101) therapy in statin-treated patients with persistent high triglycerides (from the ANCHOR study). Am J Cardiol. 2012;110:984-92.

25. Weitz D, Weintraub H, Fisher E, Schwartzbard AZ. Fish oil for the treatment of cardiovascular disease. Cardiol Rev. 2010;18:258-63.

26. Albert BB, Derraik JG, Cameron-Smith D, Hofman PL, Tumanov S, Villas-Boas SG, Garg ML, Cutfield WS. Fish oil supplements in New Zealand are highly oxidised and do not meet label content of n-3 PUFA. Sci Rep. 2015:5:7928.

27. Zargar A, Ito MK. Long chain omega-3 dietary supplements: a review of the National Library of Medicine Herbal Supplement Database. Metab Syndr Relat Disord. 2011;9:255-71. 
28. Miller M, Stone NJ, Ballantyne C, Bittner V, Criqui MH, Ginsberg HN, Goldberg AC, Howard WJ, Jacobson MS, Kris-Etherton PM, et al. Triglycerides and cardiovascular disease: a scientific statement from the American Heart Association. Circulation. 2011;123:2292-333.

29. Grundy SM, Becker D, Clark LT, Cooper RS, Denke MA, Howard JW, Hunninghake DB, Illingwirth DR, Luepker RV. Third Report of the National Cholesterol Education Program (NCEP) Expert Panel on Detection, Evaluation, and Treatment of High Blood Cholesterol in Adults (Adult Treatment Panel III) final report. Circulation. 2002;106:3143-421.

30. Jellinger PS, Smith DA, Mehta AE, Ganda O, Handelsman Y, Rodbard HW Shepherd MD, Seibel JA. American Association of Clinical Endocrinologists' guidelines for management of dyslipidemia and prevention of atherosclerosis. Endocr Pract. 2012;18 Suppl 1:1-78

31. Berglund L, Brunzell JD, Goldberg AC, Goldberg IJ, Sacks F, Murad MH, Stalenhoef AF. Evaluation and treatment of hypertriglyceridemia: an Endocrine Society clinical practice guideline. J Clin Endocrinol Metab. 2012:97:2969-89.

32. Association AD. Standards of medical care in diabetes 2014. Diabetes Care. 2014;37 Suppl 1:S14-80.

33. Chapman MJ, Ginsberg HN, Amarenco P, Andreotti F, Boren J, Catapano AL, Descamps OS, Fisher E, Kovanen PT, Kuivenhoven JA, et al. Triglyceride-rich lipoproteins and high-density lipoprotein cholesterol in patients at high risk of cardiovascular disease: evidence and guidance for management. Eur Heart J. 2011;32:1345-61.

34. Catapano AL, Reiner Z, De Backer G, Graham I, Taskinen MR, Wiklund O, Agewall S, Alegria E, Chapman M, Durrington P, et al. ESC/EAS guidelines for the management of dyslipidaemias. The Task Force for the Management of Dyslipidaemias of the European Society of Cardiology (ESC) and the European Atherosclerosis Society (EAS). Atherosclerosis. 2011;217:3-46.

35. Bays HE, Tighe AP, Sadovsky R, Davidson MH. Prescription omega-3 fatty acids and their lipid effects: physiologic mechanisms of action and clinical implications. Expert Rev Cardiovasc Ther. 2008;6:391-409.

36. Le Jossic-Corcos C, Gonthier C, Zaghini I, Logette E, Shechter I, Bournot P. Hepatic farnesyl diphosphate synthase expression is suppressed by polyunsaturated fatty acids. Biochem J. 2005;385:787-94.

37. Horton JD, Bashmakov Y, Shimomura I, Shimano H. Regulation of sterol regulatory element binding proteins in livers of fasted and refed mice. Proc Natl Acad Sci U S A. 1998;95:5987-92.

38. Harris WS, Bulchandani D. Why do omega-3 fatty acids lower serum triglycerides? Curr Opin Lipidol. 2006;17:387-93.

39. Park Y, Harris WS. Omega-3 fatty acid supplementation accelerates chylomicron triglyceride clearance. J Lipid Res. 2003;44:455-63.

40. Khan S, Minihane AM, Talmud PJ, Wright JW, Murphy MC, Williams CM, Griffin BA. Dietary long-chain n-3 PUFAs increase LPL gene expression in adipose tissue of subjects with an atherogenic lipoprotein phenotype. J Lipid Res. 2002;43:979-85.

41. Jacobson TA, Glickstein SB, Rowe JD, Soni PN. Effects of eicosapentaenoic acid and docosahexaenoic acid on low-density lipoprotein cholesterol and other lipids: a review. J Clin Lipidol. 2012;6:5-18.

42. Wei MY, Jacobson TA. Effects of eicosapentaenoic acid versus docosahexaenoic acid on serum lipids: a systematic review and meta-analysis. Curr Atheroscler Rep. 2011;13:474-83.

43. Davidson MH. Omega-3 fatty acids: new insights into the pharmacology and biology of docosahexaenoic acid, docosapentaenoic acid, and eicosapentaenoic acid. Curr Opin Lipidol. 2013;24:467-74.

44. Morton A, Furtado J, Amerine W, Kling D, Davidson M, Sacks F. The effect of omega-3 carboxylic acids on apolipoprotein CIII containing lipoproteins in moderate to severe hypertriglyceridemia. Circulation. 2014;130 Suppl 1, A16864.

45. Sacks FM, Zheng C, Cohn JS. Complexities of plasma apolipoprotein C-III metabolism. J Lipid Res. 2011;52:1067-70.

46. Bays HE, Ballantyne CM, Braeckman RA, Stirtan WG, Soni PN. Icosapent ethyl, a pure ethyl ester of eicosapentaenoic acid: effects on circulating markers of inflammation from the MARINE and ANCHOR studies. Am J Cardiovasc Drugs. 2013;13:37-46.

47. Milberg P, Frommeyer G, Kleideiter A, Fischer A, Osada N, Breithardt G, Fehr M, Eckardt L. Antiarrhythmic effects of free polyunsaturated fatty acids in an experimental model of LQT2 and LQT3 due to suppression of early afterdepolarizations and reduction of spatial and temporal dispersion of repolarization. Heart Rhythm. 2011;8:1492-500.
48. Kusunoki C, Yang L, Yoshizaki T, Nakagawa F, Ishikado A, Kondo M, Morino K, Sekine O, Ugi S, Nishio Y, et al. Omega-3 polyunsaturated fatty acid has an anti-oxidant effect via the $\mathrm{Nrf}-2 / \mathrm{HO}-1$ pathway in 3T3-L1 adipocytes. Biochem Biophys Res Commun. 2013;430:225-30.

49. Okumura T, Fujioka Y, Morimoto S, Tsuboi S, Masai M, Tsujino T, Ohyanagi $M$, Iwasaki T. Eicosapentaenoic acid improves endothelial function in hypertriglyceridemic subjects despite increased lipid oxidizability. Am J Med Sci. 2002;324:247-53.

50. Engler MM, Engler MB, Malloy M, Chiu E, Besio D, Paul S, Stuehlinger M, Morrow J, Ridker P, Rifai N, Mietus-Snyder M. Docosahexaenoic acid restores endothelial function in children with hyperlipidemia: results from the EARLY study. Int J Clin Pharmacol Ther. 2004;42:672-9.

51. Lee MW, Park JK, Hong JW, Kim KJ, Shin DY, Ahn CW, Song YD, Cho HK, Park SW, Lee EJ. Beneficial effects of omega-3 fatty acids on low density lipoprotein particle size in patients with type 2 diabetes already under statin therapy. Diabetes Metab J. 2013;37:207-11.

52. Serebruany $\mathrm{VL}$, Miller M, Pokov AN, Lynch D, Jensen JK, Hallen J, Atar D. Early impact of prescription omega-3 fatty acids on platelet biomarkers in patients with coronary artery disease and hypertriglyceridemia. Cardiology. 2011;118:187-94.

53. Woodman RJ, Mori TA, Burke V, Puddey IB, Barden A, Watts GF, Beilin LJ. Effects of purified eicosapentaenoic acid and docosahexaenoic acid on platelet, fibrinolytic and vascular function in hypertensive type 2 diabetic patients. Atherosclerosis. 2003;166:85-93.

54. Mori TA, Bao DQ, Burke V, Puddey IB, Beilin LJ. Docosahexaenoic acid but not eicosapentaenoic acid lowers ambulatory blood pressure and heart rate in humans. Hypertension. 1999;34:253-60.

55. Stark KD, Holub BJ. Differential eicosapentaenoic acid elevations and altered cardiovascular disease risk factor responses after supplementation with docosahexaenoic acid in postmenopausal women receiving and not receiving hormone replacement therapy. Am J Clin Nutr. 2004;79:765-73.

56. Theobald HE, Goodall AH, Sattar N, Talbot DC, Chowienczyk PJ, Sanders TA. Low-dose docosahexaenoic acid lowers diastolic blood pressure in middle-aged men and women. J Nutr. 2007;137:973-8.

57. Lauritzen L, Brambilla P, Mazzocchi A, Harslof LB, Ciappolino V, Agostoni C. DHA effects in brain development and function. Nutrients 2016; 8

58. Hino A, Adachi H, Toyomasu K, Yoshida N, Enomoto M, Hiratsuka A, Hirai Y, Satoh A, Imaizumi T. Very long chain N-3 fatty acids intake and carotid atherosclerosis: an epidemiological study evaluated by ultrasonography. Atherosclerosis. 2004;176:145-9.

59. Cawood AL, Ding R, Napper FL, Young RH, Williams JA, Ward MJ, Gudmundsen O, Vige R, Payne SP, Ye S, et al. Eicosapentaenoic acid (EPA) from highly concentrated n-3 fatty acid ethyl esters is incorporated into advanced atherosclerotic plaques and higher plaque EPA is associated with decreased plaque inflammation and increased stability. Atherosclerosis. 2010;212:252-9.

60. Nordestgaard BG, Varbo A. Triglycerides and cardiovascular disease. Lancet. 2014;384:626-35.

61. Simon JA, Hodgkins ML, Browner WS, Neuhaus JM, Bernert JJ, Hulley SB. Serum fatty acids and the risk of coronary heart disease. Am J Epidemiol. 1995:142:469-76.

62. Sun Q, Ma J, Campos H, Rexrode KM, Albert CM, Mozaffarian D, Hu FB. Blood concentrations of individual long-chain n-3 fatty acids and risk of nonfatal myocardial infarction. Am J Clin Nutr. 2008;88:216-23.

63. Amano T, Matsubara T, Uetani T, Kato M, Kato B, Yoshida T, Harada K, Kumagai S, Kunimura A, Shinbo Y, et al. Impact of omega-3 polyunsaturated fatty acids on coronary plaque instability: an integrated backscatter intravascular ultrasound study. Atherosclerosis. 2011;218:110-6.

64. Leng GC, Horrobin DF, Fowkes FG, Smith FB, Lowe GD, Donnan PT, Ells K. Plasma essential fatty acids, cigarette smoking, and dietary antioxidants in peripheral arterial disease. A population-based case-control study. Arterioscler Thromb. 1994;14:471-8.

65. Akiba S, Murata T, Kitatani K, Sato T. Involvement of lipoxygenase pathway in docosapentaenoic acid-induced inhibition of platelet aggregation. Biol Pharm Bull. 2000:23:1293-7.

66. Kishida E, Tajiri M, Masuzawa Y. Docosahexaenoic acid enrichment can reduce $L 929$ cell necrosis induced by tumor necrosis factor. Biochim Biophys Acta. 2006;1761:454-62.

67. Chan DC, Watts GF, Barrett PH, Beilin LJ, Redgrave TG, Mori TA. Regulatory effects of HMG CoA reductase inhibitor and fish oils on apolipoprotein 
B-100 kinetics in insulin-resistant obese male subjects with dyslipidemia. Diabetes. 2002;51:2377-86.

68. Davidson MH, Johnson J, Rooney MW, Kyle ML, Kling DF. A novel omega-3 free fatty acid formulation has dramatically improved bioavailability during a low-fat diet compared with omega-3-acid ethyl esters: the ECLIPSE

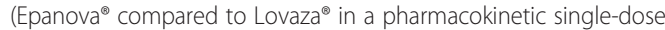
evaluation) study. J Clin Lipidol. 2012;6:573-84.

69. Tsujita T, Okuda H. The synthesis of fatty acid ethyl ester by carboxylester lipase. Eur J Biochem. 1994;224:57-62.

70. Hui DY, Howles PN. Carboxyl ester lipase: structure-function relationship and physiological role in lipoprotein metabolism and atherosclerosis. J Lipid Res. 2002:43:2017-30.

71. Ikeda I, Sasaki E, Yasunami H, Nomiyama S, Nakayama M, Sugano M, Imaizumi K, Yazawa K. Digestion and lymphatic transport of eicosapentaenoic and docosahexaenoic acids given in the form of triacylglycerol, free acid and ethyl ester in rats. Biochim Biophys Acta. 1995;1259:297-304.

72. Beckermann B, Beneke M, Seitz I. [Comparative bioavailability of eicosapentaenoic acid and docasahexaenoic acid from triglycerides, free fatty acids and ethyl esters in volunteers]. Arzneimittelforschung. 1990;40:700-4

73. Balk EM, Lichtenstein AH, Chung M, Kupelnick B, Chew P, Lau J. Effects of omega-3 fatty acids on serum markers of cardiovascular disease risk: a systematic review. Atherosclerosis. 2006;189:19-30.

74. Clinicaltrials.gov. A Study of AMR101 to Evaluate Its Ability to Reduce Cardiovascular Events in High Risk Patients With Hypertriglyceridemia and on Statin. The Primary Objective is to Evaluate the Effect of $4 \mathrm{~g} /$ Day AMR101 for Preventing the Occurrence of a First Major Cardiovascular Event. (REDUCE-IT). Available at: https://clinicaltrials.gov/ct2/show/ NCT01492361. Accessed: 24 Nov 2015.

75. Clinicaltrials.gov. Outcomes Study to Assess STatin Residual Risk Reduction With EpaNova in HiGh CV Risk PatienTs With Hypertriglyceridemia (STRENGTH). Available at: https://clinicaltrials.gov/ct2/show/NCT02104817. Accessed: 24 Nov 2015.

76. Expert Panel on Integrated Guidelines for Cardiovascular Health and Risk Reduction in Children and Adolescents. Expert panel on integrated guidelines for cardiovascular health and risk reduction in children and adolescents: summary report. Pediatrics. 2011;128 Suppl 5:S213-56.

77. Skilton MR, Ayer JG, Harmer JA, Webb K, Leeder SR, Marks GB, Celermajer DS. Impaired fetal growth and arterial wall thickening: a randomized trial of omega-3 supplementation. Pediatrics. 2012;129:e698-703.

78. Forsyth JS, Willatts P, Agostoni C, Bissenden J, Casaer P, Boehm G. Long chain polyunsaturated fatty acid supplementation in infant formula and blood pressure in later childhood: follow up of a randomised controlled trial. BMJ. 2003;326:953.

79. Skilton MR, Raitakari OT, Celermajer DS. High intake of dietary long-chain omega-3 fatty acids is associated with lower blood pressure in children born with low birth weight: NHANES 2003-2008. Hypertension. 2013;61:972-6.

80. Ciccone MM, Scicchitano P, Gesualdo M, Zito A, Carbonara S, Ricci G, Cortese F, Giordano P. The role of omega-3 polyunsaturated fatty acids supplementation in childhood: a review. Recent Pat Cardiovasc Drug Discov. 2013;8:42-55.

81. Filion KB, El Khoury F, Bielinski M, Schiller I, Dendukuri N, Brophy JM. Omega-3 fatty acids in high-risk cardiovascular patients: a meta-analysis of randomized controlled trials. BMC Cardiovasc Disord. 2010;10:24.

82. McKenney JM, Swearingen D, Di SM, Doyle R, Pantaleon C, Kling D, Shalwitz RA. Study of the pharmacokinetic interaction between simvastatin and prescription omega-3-acid ethyl esters. J Clin Pharmacol. 2006;46:785-91.

83. Di Spirito M, Morelli G, Doyle RT, Johnson J, McKenney J. Effect of omega-3-acid ethyl esters on steady-state plasma pharmacokinetics of atorvastatin in healthy adults. Expert Opin Pharmacother. 2008;9:2939-45.

84. Kostapanos MS, Milionis HJ, Elisaf MS. Rosuvastatin-associated adverse effects and drug-drug interactions in the clinical setting of dyslipidemia. Am J Cardiovasc Drugs. 2010;10:11-28.

85. Durrington PN, Bhatnagar D, Mackness MI, Morgan J, Julier K, Khan MA, France M. An omega-3 polyunsaturated fatty acid concentrate administered for one year decreased triglycerides in simvastatin treated patients with coronary heart disease and persisting hypertriglyceridaemia. Heart. 2001;85:544-8.

86. Bays HE, McKenney J, Maki KC, Doyle RT, Carter RN, Stein E. Effects of prescription omega-3-acid ethyl esters on non-high-density lipoprotein cholesterol when coadministered with escalating doses of atorvastatin. Mayo Clin Proc. 2010;85:122-8.

87. Bays HE. Safety considerations with omega-3 fatty acid therapy. Am J Cardiol. 2007:99:35C-43C.

88. Harris WS. Expert opinion: omega-3 fatty acids and bleeding - cause for concern? Am J Cardiol. 2007;99:44C-6C

89. Davidson MH, Marenco T, Honstein A, Johnson J, Kling D. Multiple-dose administration of a free-fatty acid formulation or EPA/DHA has no effect on the pharmacokinetics or pharmacodynamics of single-dose warfarin. In 2012 AAPS Annual Meeting and Exposition. Abstract T2284

90. Braeckman RA, Stirtan WG, Soni PN. Phase 1 study of the effect of icosapent ethyl on warfarin pharmacokinetic and anticoagulation parameters. Clin Drug Investig. 2014;34:449-56.

91. Barnes PM, Bloom B, Nahin RL. Complementary and alternative medicine use among adults and children: United States, 2007. Natl Health Stat Report. 2008;12:1-23.

92. Omega-3 oil: fish or pills? Consum Rep 2003;68:30-32. No authors listed.

93. Weintraub HS. Overview of prescription omega-3 fatty acid products for hypertriglyceridemia. Postgrad Med. 2014;126:7-18.

94. Mozaffarian D, Rimm EB. Fish intake, contaminants, and human health: evaluating the risks and the benefits. JAMA. 2006;296:1885-99.

95. Kris-Etherton PM, Harris WS, Appel L. Fish consumption, fish oil, omega-3 fatty acids, and cardiovascular disease. Circulation. 2002;106:2747-57.

96. Holub BJ. Clinical nutrition: 4. Omega-3 fatty acids in cardiovascular care. CMAJ. 2002;166:608-15.

97. Scicchitano P, Cameli M, Maiello M, Modesti P, Muiesan M, Novo S, Palmiero P, Saba P, Pedrinelli R, Ciccone M. Nutraceuticals and dyslipidaemia: beyond the common therapeutics. J Funct Foods. 2014;6:11-32.

\section{Submit your next manuscript to BioMed Central and we will help you at every step:}

- We accept pre-submission inquiries

- Our selector tool helps you to find the most relevant journal

- We provide round the clock customer support

- Convenient online submission

- Thorough peer review

- Inclusion in PubMed and all major indexing services

- Maximum visibility for your research

Submit your manuscript at www.biomedcentral.com/submit
( ) BioMed Central 